\title{
Experiência POP RUA: Implementação do "Saúde em Movimento nas Ruas" no Rio de Janeiro, um Dispositivo Clínico/Político na Rede de Saúde do Rio de Janeiro
}

Experience POP STREET: Implementation of "Health in Motion on the Streets" in Rio de Janeiro, a Clinical/Political Device in the Health System of the Rio de Janeiro Experiencia POP CALLE: Aplicación de la "Salud en Movimiento en las Calles" en Río de Janeiro, un Dispositivo Clínico/Política en el Sistema De Salud de Río de Janeiro

\section{Iacã Machado Macerata}

Universidade Federal Fluminense, Niteroi, RJ, Brasil.

\section{Resumo}

Este texto tem função de expressar, apresentar e discorrer acerca da experiência do projeto "Saúde em Movimento nas Ruas", também conhecido como ESF POP RUA. Este serviço serviu de modelo para as Equipes de Consultório na Rua do Ministério da Saúde. No ano de 2010, ano de sua implementação, se configurava como um serviço híbrido e inédito, serviço que reunia Atenção Básica em saúde, Saúde Mental e Redução de Danos. Desde sua implementação o serviço vem se constituindo como uma referência em saúde pública para população em situação de rua nas redes de políticas públicas na cidade do Rio de Janeiro. A experiência é contada a partir da ótica do gerente técnico da equipe, em seu primeiro ano de implementação.

Palavras chave: População em situação de rua; Atenção básica; Saúde mental; Redução de danos.

\begin{abstract}
This text presents the experience of "Saúde em Movimento nas Ruas" (can be translate by Health in Motion in the Streets), also known as ESF POP RUA. This service started in 2010, was configured as a hybrid service and unprecedented service that gathered Primary Health, Mental Health and Harm Reduction. Since its inception the service has been constituted as a reference in public health for the homeless population in policy networks in the city of Rio de Janeiro. The experience is told from the perspective of the technical manager of the team in its first year of implementation.
\end{abstract}

Keywords: People on the streets; Primary health; Mental health, Harm reduction. 


\section{Resumen}

Este texto sirve para expresar, presentar y discutir la experiencia de "La salud en movimiento en las calles”, también conocido como ESF POP RUA. Este servicio era un modelo para lãs equipos de “Consultório na Rua” del Ministerio de Salud en 2010, el año de su implementación, se ha configurado como un servicio híbrido y servicio sin precedentes que reunió atención primária, Salud Mental y Reducción de Daños . Desde su creación, el servicio se ha constituido como un referente en la salud pública de la población sin hogar en las redes de política en la ciudad de Rio de Janeiro. La experiencia es contada desde la perspectiva del director técnico del equipo en su primer año de ejecución.

Palabras clave: Población sin hogar; Atención primaria; Salud mental, Reducción de daños.

\section{1-Montagem}

O SMR ("Saúde em Movimento nas Ruas" e também conhecido como ESF POP RUA) é um serviço de saúde que atende pessoas de todas as idades que estão em situação de rua, no centro da cidade do Rio de Janeiro. Este serviço é um dispositivo que se produz na associação e na mistura entre dois tipos de equipamento, produzindo um terceiro: o SMR nasce em setembro de 2010, conjugando duas equipes de Estratégia de Saúde da Família e o projeto Consultório de Rua, tendo em seu corpo os seguintes profissionais: médico, enfermeiro, técnico de enfermagem, Agentes Comunitários de Saúde Rua (ACS RUA) e odontólogo, associados a uma equipe multiprofissional de saúde mental: psicólogo, assistente social e musicoterapeuta. Tendo como público alvo todo tipo de população que tem na rua seu território de existência e vivência principal (moradores de rua, crianças e jovens em situação de rua, famílias residentes de ocupações, profissionais do sexo, trabalhadores de rua), o serviço atua no Centro da cidade do Rio de Janeiro, funcionando de $9 \mathrm{~h}$ às $22 \mathrm{~h}$, de segunda à sexta, e fazendo parte do Centro Municipal de Saúde Oswaldo Cruz (CMSOC).

Este relato se refere ao primeiro ano de implementação do serviço, onde participei como Gerente Técnico da equipe. Tal experiência é anterior a formulação das atuais equipes de Consultório na Rua ${ }^{1}$ (eCNR), tendo inclusive servido de uma das bases para a formulação das novas eCNR.

Para a implementação de tal serviço, uma equipe multiprofissional foi montada com profissionais que tivessem experiência e interesse no trabalho com a rua. A equipe de Agente Comunitário de Saúde é a expres- 
são maior da fundamentação deste serviço de saúde a partir de uma experiência com a rua, fator que reforça seu caráter híbrido: se na Saúde da Família tradicional o ACS pertence à comunidade, no SMR o ACS tem familiaridade com a rua, sendo que a sua maioria trabalhou anteriormente como educador social de rua, e/ou até já esteve em situação de rua. A experiência com e na rua denota uma capacidade comunicacional com a dinâmica deste território, evidenciando a direção necessariamente ascendente da política pública: a sustentação nas experiências que se constituem nos território de vida singulares. A construção da política deve se fazer a partir do plano relacional que as equipes constituem com o território alvo da intervenção, uma direção ascendente: do cotidiano de vida concreto para os locais de formulação e gestão das políticas.

Se o SMR teve que estruturar suas ações a partir do território, fazia-se necessário estar presente, sensível as dinâmicas territoriais, através da produção de um saber com o território da rua. O primeiro momento da montagem do aparelho foi de mapeamento, ou melhor, de construção de uma cartografia territorial a ser constantemente atualizada pela equipe. Essa cartografia dizia respeito a uma apropriação do território por parte da equipe. Os primeiros dois meses de trabalho consistiram em saídas a campo onde toda a equipe passava o dia Rev. Polis e Psique, 2013; 3(2):207-219 na rua e, ao final do dia, produzia um mapa do território, através de um desenho que ia se atualizando e sendo construído coletivamente. Tal prática cartográfica permaneceu durante todo o primeiro ano do serviço, sendo incluída nos processos de discussão de caso e nas reuniões de discussão territorial. Essas saídas a campo iniciais e a constante atualização da imagem do território para a equipe estruturaram as bases de atuação dos ACS RUA.

A atuação dos ACS RUA se organizou através de micro áreas constantemente redefinidas, na região do Centro da cidade do Rio de Janeiro, a partir da concentração de população de rua e suas flutuações. Se o ACS RUA tem uma função central na montagem do serviço é pela capacidade que esta função tem de promover pontes comunicacionais entre a lógica da instituição e a lógica da rua: se as redes de políticas públicas operam através de um tempo e um modo de distribuição no espaço muito bem definidos e delimitados, com uma definição clara entre interior e exterior, o tempo e o espaço da rua tem suas linhas demarcatórias muito menos fixas: onde começa e onde termina a morada de uma pessoa que mora na rua? Em que relação com o tempo e com o espaço sua subjetividade se constitui?

Há, portanto, uma distância entre o regime espaço temporal da da máquina estatal e das vidas que se produzem no território 
da rua. Essa distância exige um tipo especial de serviço que é personificado na figura do ACS RUA. Ele precisa ao mesmo tempo de uma capacidade de entender e manejar com a fluidez e a velocidade da rua, trabalhar com uma dinâmica própria da rua, e dar conta de construir metodologias e estratégias que permitam que a lógica do serviço possa se conectar com lógica da rua: se os serviços tem um horário de funcionamento, com agenciamentos, horário de acolhimento, muitos moradores de rua não funcionam na ordem deste tempo institucional. O ACS Rua tem a função de trabalhar junto as instituições e as pessoas que vivem na rua no sentido facilitar pontos de encontro, convergências. O ACS RUA é uma ponte, em um serviço que se propõe ser ponte. $\mathrm{O}$ trabalho do serviço se desenvolve a partir do vínculo constituído com a população de rua, e o ACS é a primeira instância da equipe a chegar nesta população, articulando redes institucionais e comunitárias, formais e informais. É a partir da atuação e presença do ACS no território de abrangência que serão efetuadas as aproximações junto à população em situação de rua. A partir destas aproximações é que serão feitos os encaminhamentos para a equipe técnica, tanto na rua quanto no CMSOC.

Assim, o SMR tem dois mecanismos de encontro com seu público: a primeira é através das aproximações na rua feitas pelos
ACS; a segunda é através da porta de entrada no serviço, o chamado acolhimento, realizado por enfermeiro, técnico de enfermagem, assistente social e um ACS, onde os pacientes são acolhidos no CMSOC, sendo avaliados e agendados para os atendimentos diversos. Este processo é baseado na criação do vínculo com a população, que vai permitir um tratamento baseado no processo de acompanhamento, tentando escapar às ações pontuais, e buscando centrar-se na construção de demandas a serem atendidas longitudinalmente, transversalmente através de diversos olhares e saberes da equipe.

O SMR tem como público alvo uma população "estranha" aos serviços de saúde e um território de lógicas diversas das que a saúde está acostumada a lidar. Historicamente as políticas de saúde, assim como as demais políticas, pouco atuaram junto a população de rua, relegando este público a política de Assistência Social ou a Polícia. Esta exclusão está ligada a diferença que a vida da rua expressa na cidade: a vida de rua é um modo de vida que escapa aos padrões estabelecidos de moradia, configuração familiar, inserção no mercado de traba1ho, consumo, etc. Esta diferença é talvez um importante analisador dos operadores e noções que as políticas de saúde utilizam como bailadores de sua prática. Em nossa experiência, era muito comum ouvir dos equipamentos de saúde que eles não aten- 
deriam os moradores de rua pois para tratar sua saúde, era antes preciso que ele deixasse a rua e morasse em uma casa. A saúde ainda opera através de um olhar de matriz domiciliar.

Pois é justamente contra um purismo, contra uma matriz que se pretende natural, saudável, que o SMR se constituiu como dispositivo que não é a soma, sobreposição ou paralelismo de dois serviços, mas sim uma mistura, um híbrido para lidar com um público e um território híbrido e diverso. Essa estranha composição tem como objetivo principal a efetivação de dois princípios muito conhecidos do SUS, e hegemonicamente negado ao território da rua: o acesso universal, que entendemos como o acesso de qualquer um que do SUS necessite, e a equidade na atenção, que entendemos ser a construção e adaptação dos serviços de saúde as realidades singulares presentes em cada território, e não o exercício de protocolos e diretrizes pré formadas.

\section{2-Hibridez}

Ampliar o acesso para esta população passa, em função de toda uma conjuntura da rede de saúde e da sociedade, pela constituição de um serviço capaz de se conectar e acolher demandas de saúde - demandas do viver - extremamente complexas, diversas e singulares.
Em sendo não dois serviços colados, mas um terceiro, no SMR os saberes e as funções dos tipos de atenções em saúde (saúde da família e saúde mental), se hibridizam, fazendo com que os atendimentos, os fluxos, os protocolos clínicos, as articulações funcionem de formas diferenciadas do já posto no âmbito do PSF (atenção básica) e do Consultório de Rua (saúde mental). Porém, nestas misturas e associações de várias ordens (da saberes, de experiências, de natureza de atenção, etc.), algo liga e conecta diretamente o "Consultório de Rua", que trabalha numa perspectiva de Redução de Danos, à Estratégia de Saúde da Família. O que permite esta conexão e esta mistura, e faz com que os dois possam produzir um terceiro e não um amontoado de ações que não “conversam"? Há uma conexão, que é a de uma certa lógica no que poderíamos chamar de metodologia.

O SMR mantém a função-diretriz do Saúde da Família: ser a porta de entrada para a SUS, atender e promover a saúde a partir do território onde determinada população vive; trabalhar a produção de saúde a partir da experiência singular de cada território, a partir do cotidiano de vida das pessoas. Esta lógica do SF vem ao encontro à lógica do trabalho da Redução de Danos no contexto do Consultório de Rua: vamos entender por Redução de Danos a promoção da saúde a partir da singularidade de cada 
sujeito e cada território, e a partir de seus funcionamentos, condições e características; a construção de estratégias que possibilitem uma ampliação do grau de saúde, da qualidade de vida, a partir da singularidade de cada sujeito, de cada micro comunidade, de cada momento de seu processo de vida.

Se o Saúde da Família tem como prerrogativa atuar onde as dinâmicas dos cotidianos e processos relativos a saúde das pessoas se localizam, a Redução de Danos entra como mais um olhar, mais um conjunto de saberes que incluiria a atenção para outra dimensão da saúde (geralmente é separada e destinada a saúde mental, sob a forma de "doenças", desvios e disfunções), o que poderíamos chamar de dimensão subjetiva das expressões da saúde. O Consultório de Rua acopla-se ao Saúde da Família, estendendo a atenção aos processos locais de saúde/doença também com o olhar acerca do "subjetivo" nestes processos, nestas dinâmicas.

Amplia-se assim a gama de demandas "acompanháveis" a serem levadas em consideração, e mais que isso, vai-se entender que as dinâmicas subjetivas de cada sujeito ou comunidade e a saúde do corpo estão totalmente entrelaçadas na realidade e no cotidiano dessas vidas. Se para o Saúde da Família tradicional, atualmente e geralmente, é difícil atender as demandas da comunidade no que diz respeito a, por Rev. Polis e Psique, 2013; 3(2):207-219 exemplo, o abuso do uso de substâncias psicoativas e os transtornos mentais graves, a inclusão do Consultório de Rua amplia a possibilidade de atendimento destas demandas em um serviço de atenção básica. E ainda, o instrumental de uma equipe de saúde mental atuando junto e de forma entrelaçada a uma equipe de saúde da família faz com que o que antes era objeto restrito de uma ou de outra possa ser entendido como totalmente relacionado.

Assim, o Consultório de Rua entra no Saúde da Família para ancorar na equipe os conceitos de Redução de Danos em seu sentido ampliado. Tomando esta lógica que liga os dois tipos de serviço, a metodologia de trabalho é produzida a partir do encontro com o território e sua população, e tem como sustentação a construção e produção de vínculos e relacionamentos que transcendam o simples atendimento às pessoas em vulnerabilidade, e na produção de ações que possam potencializar a saúde a partir de suas singularidades, singularizando o projeto terapêutico de cada caso.

A grande Redução de Danos aqui sendo experimentada é descobrir quais dos caminhos possíveis, dentro do serviço público, de tão fechadas portas para estes usuários, podem representar ampliação de vida, apontar alguns horizontes, significar esperança e alegria: mais uma posição na rela- 
ção com o paciente do que uma prática de oferecer insumos.

É na mistura, na associação entre políticas, entre saberes, entre experiências, na vinculação entre o que "já está posto" e "o novo a ser construído e estabelecido" que essa práxis, de cunho histórico fundamental tem sua referência. A aposta efetuada a partir destas misturas (e que ao mesmo tempo permite estas misturas) é a aposta no respeito e no acolhimento às mais diversas formas de vida, como via de produção de saúde e também como um modo de produção de uma sociedade mais diversa, acolhedora e ética: o que podemos chamar de uma aposta clínico/política.

\section{3-Vetor "rua" no contexto do Rio de} Janeiro

Mas, ao incorporamos os princípios do SUS, devemos nos perguntar: Porque um serviço de saúde específico para situação de rua, se a rede de atendimento do SUS deve atender todo cidadão? Certamente a ideia da rede não deve ser produzir serviços cada vez mais especializados, correndo o risco de marcar mais desigualdades e operar divisões. Porém, como já colocamos, este atendimento, ou esta clínica que se produz neste serviço é inseparável da política. Toda intervenção política é datada, ou seja, tem seu sentido construído a partir de uma certa configuração de um diagrama de forças, de paisagens sociais. Isso nos coloca a questão do lugar que a rua se encontra na cidade contemporânea, e ainda, especificamente na cidade do Rio de Janeiro.

Em minha pesquisa (Macerata, 2010) vim entendo a rua como um "fora/ dentro" da cidade, um espaço existencial envolvido pela cidade, mas que todavia, escapa a suas leis e suas dinâmicas oficias. É o lado de fora das formas oficiais da cidade. Em nossa experiência no SMR entendemos que a rua acaba sendo o lugar de tudo que não tem lugar na cidade: o que não cabe nas casas da classe média, o que não cabe na comunidade. Não só a miséria leva as pessoas à rua. Uma conjunção de fatores produz este território existencial.

A rua se constitui então como esta zona "obscura" na cidade, zona estrangeira, "estranha/íntima" na cidade. A rua como fora/dentro da cidade marca distâncias entre cidades em uma mesma cidade. $\mathrm{O}$ arquiteto Fernando Fuão (2001), compara a rua com os abismos dos cânions: a rua como um corte, uma rachadura na cidade. Corte que deixa em evidência a composição, os modos de funcionamento da cidade, espaço onde as dinâmicas sociais são explicitadas, e justamente por esta explicitação talvez, a rua seja um espaço tanto evitado e temido quanto fascinante. 
As lógicas hegemônicas e mais instituídas da cidade conseguem manter poucos pontos de comunicação com este território existencial. Vemos modos de intervenção com a população de rua, que na sua grande maioria tentam lidar com a rua de duas formas: a primeira é a de simples inclusão das pessoas em situação de rua, com o objetivo de moldar e adaptar seus modos de vida aos modos considerados normais, ou "saudáveis"; a segunda é de uma relação de isolamento ou extermínio. Atualmente, vemos o aumento assustador do número de práticas de higienização da cidade, aplaudias por uma opinião pública que não sabe como lidar com esta situação, a não ser através do olhar judicativo binário “certo/errado". De qualquer forma, todos estes modos de intervenção estabelecem uma forma de relação: a de pouca ou nenhuma troca, um modo de relação que chamei de antagonista, onde se pressupõe a eliminação do outro, do diferente, ou uma "não-relação".

Nossa proposição vai em outro sentido, e atenta principalmente não para a forma da ação, mas para o modo como se coloca a ação em prática, ou seja, a relação. Este espaço relacional é nosso alvo, nosso campo de possibilidade: como se postar nesta relação? Que ética nos conduz nesta prática? Podemos dizer uma ética de acolhimento à diferença e de produção de diferença, a partir da realidade e do respeito aos mais diversos modos de ser e estar na cidade. Promover saúde como modo de produzir cidadania: não a cidadania como um modelo do indivíduo moderno, mas cidadania se aproximando da produção de subjetividade: ampliar os modos de habitar a cidade e os modos de fazer parte da sociedade. A saúde é uma via de construção de modos de vida outros, portanto os efeitos são de ampliação de possibilidades para o usuário atendido mas também para a cidade.

Neste sentido a intervenção é clínica e política ao mesmo tempo: acolhimento e produção de desvio, tanto do público alvo, quanto da rede que propõe a intervenção. Assim, este dispositivo é eminentemente político na rede de saúde do Rio de Janeiro: ele vai colocar em evidência os furos da rede no atendimento da diversidade - no caso da rua a diversidade e a manifestação da complexidade (demandas objetivas e subjetivas entrelaçadas) levada ao limite dentro da cidade; ele vai exigir da rede a construção de outros fluxos; ele vai exigir que a rede amplie o sentido do que é um cidadão, de certas concepções de doença e do modo como saúde física e saúde mental estão, no real, totalmente inseparáveis.

\section{4-Dimensão pública da política}

Ao empreendermos um necessário reencantamento da noção de público, esta 
parece ser a função da política pública: ampliar o espaço de comunicação entre as diferenças, sustentar espaços para a diversidade e sustentar o acolhimento e a produção de diversidade, afirmar o diferente como existência legítima, e só assim, a partir deste acolhimento real, produzir saúde e ampliar as qualidades de vidas diversas.

É desta relação de atenção, respeito e presença, deste estar em relação "com" que é possível construir ações que atendam as demandas do público, e da diversidade que constitui o público. A demanda a ser respondida não deve advir dos gabinetes dos "tecnocratas"; a demanda também não é a queixa inicial do público alvo. A demanda na política pública de saúde que se sustenta nestes preceitos que viemos falando, é construída na relação dos serviços com o público, ela não está dada nem de um lado nem de outro.

A função da política efetivamente pública é construir pontes, que impliquem aquele que intervém e aquele que é alvo da intervenção. Uma mútua implicação transforma tanto aquele que intervém quanto o alvo da intervenção. No caso do SMR, a intervenção deve produzir mudanças e alterações tanto na população de rua quanto nas redes de saúde, na cidade. Construir pontes entre as várias cidades que compõe o cenário do Rio de Janeiro pode ser um modo mais ético de alterar a realidade da cidade.
E como já falamos, a saúde é nossa via para tanto.

Pois, se a rua do Rio de Janeiro presencia tanta violência, abandono, doença, extermínios (diretos e indiretos), é porque estes elementos estão não só na rua, mas disseminados nos mais diversos espaços da cidade (geralmente os mais oficiais) com modos diferentes de expressão. A rua como já falamos não é um espaço apartado da cidade, mas ela coloca em evidência alguns produtos do modo de funcionamento da cidade. A rua torna evidente o que a cidade não quer ver. Mas a rua, em sendo o lado de fora (dentro) da cidade, é também um território de intensidades outras, uma dimensão da realidade urbana que tem também alto poder elucidativo: a rua, entre outras “vislumbrações", impele, pela gravidade de suas demandas, a um olhar transversal.

\section{5-Olhar transversal}

$\mathrm{Na}$ rua as questões de saúde como ferimentos, enfermidades como tuberculose, HIV, estão associadas a transtornos mentais graves, abuso de substâncias psicoativas, vulnerabilidades sociais extremas. A complexidade destas questões de saúde que a rua apresenta, evidencia a inseparabilidade entre saúde física e saúde mental, fazendo do tratamento uma tarefa eminentemente transversal, devido à gravidade das situa- 
ções e ao entrelaçamento de várias naturezas de enfermidades.

Por isso a importância de um olhar acerca da saúde que conecte e transversalize diversos saberes: saúde mental, redução de dados, saúde da família, experiência de rua. A novidade da junção de profissionais de saúde mental na atenção básica permite que a saúde da família incorpore a saúde mental, o que pode nos direcionar cada vez mais para uma visão transversal de saúde. $\mathrm{O}$ SMR é um dos primeiros serviços da atenção básica a ter profissionais de saúde mental atuando diretamente com a equipe de Saúde da Família.

Os atendimentos individuais e coletivos no CMS e na Rua da equipe de saúde mental, assim como os grupos de ações de promoção em saúde, o matriciamento da equipe, a discussão interdisciplinar de casos, a presença nos plantões de acolhimento e nos grupos técnicos de gestão compartilhada, têm permitido uma ação integrada no atendimento dos casos, na formação da equipe e na construção coletiva do projeto de gestão e da metodologia de atenção (construir a metodologia a partir da ponta). A atuação associada entre os profissionais fortalece a equipe como coletivo, reforçando o viés da clínica ampliada e da atenção/cuidado a saúde integral da pessoa em situação de rua. Cada acompanhamento de caso, trabalhado em parceria por agentes comunitários, médiRev. Polis e Psique, 2013;3(2):207-219 co e enfermeiros e técnicos de saúde mental visa à atenção aos aspectos múltiplos da história de vida de cada paciente.

O SMR, em 10 meses de funcionamento, conseguiu uma inserção ímpar no contexto da Rua do Centro do Rio de Janeiro. O serviço tornou-se, em pouco tempo, referência destacada para a população de rua, não só no que diz respeito à saúde. Instituições, ONG's, serviços públicos, movimentos sociais que atuam nas áreas da saúde, assistência social, segurança pública, direitos humanos, encaminham pacientes para o acolhimento do SMR, e referenciam o serviço para atendimento das demandas da população de rua e para a atuação e militância em diversos espaços políticos da cidade - comitê de população de rua da câmara de vereadores do Rio de Janeiro, Centros de defesa de direitos humanos, fórum estadual de população de rua, etc. O SMR também atua no sentido de trabalhar as redes de serviços públicos a receber e a atender esta população, dando, muitas vezes, apoio técnico a instituições e serviços.

O SMR tornou-se referência para sua população alvo, tanto pela pouca oferta de serviço a esta população, pela maneira como esta população vem sendo excluída na cidade do Rio de Janeiro, como pela maneira pela qual a equipe atua com esta população e produz processos de cuidado: atuando de maneira a respeitar os proces- 
sos e expressões de vida e ao mesmo tempo comprometida clínica e politicamente com a população. Conseguindo falar uma língua comum (construir um comum) à população em situação de rua, o SMR entende que o cuidado se produz por uma relação de troca, atenção e escuta, onde a saída da rua não é um processo rápido e imediato, mas sim a construção de outros sentidos de vida, através do comprometimento de cada pessoa com sua saúde, com sua história, com seu território.

O SMR vem conseguindo uma adesão importante dos pacientes em seus tratamentos. Os pacientes tomam a medicação, vêm às consultas com a psicóloga, com a assistente social, nos grupos de musico terapia, às consultas médicas, etc. $\mathrm{O}$ serviço vem conseguindo também, algo que não ocorria facilmente na rede de saúde da cidade do Rio de Janeiro: a inserção desta população de rua na rede de serviços de saúde e dentro dos equipamentos e prédios dos serviços de saúde. Neste sentido, entendemos que é clínico/politicamente fundamental não só atender o paciente na rua, mas mostrar a ele e a população em geral, que o espaço do Centro de Saúde é também daquele que se encontra em situação de rua: pois, para a pessoa em situação de rua, se produz mais uma referência de cuidado em seu território, se oferta a possibilidade de um exercício de cidadania que é contar com um es- paço público de saúde, que deixa de ser uma palavra de ordem para se tornar um direito experienciável; para a população em geral e para a cidade pois inclui nos espaços coletivos outros modos de vida, outras perspectivas da cidade, o que traz a possibilidade de ampliação da capacidade de conviver com as diferenças. Isso experimentamos concretamente, não sem embates, no processo de construção de um espaço para a rua e suas vidas dentro do Centro Municipal de Saúde: um fora/dentro.

\section{6-A rua como via de transformação da cidade}

A rua como se configura na cidade do Rio de Janeiro, com toda gravidade e complexidade que apresenta, tem o potencial de produzir outras linhas de cuidado, de mostrar a necessidade de reposicionamentos técnicos e políticos das redes de saúde e das redes de políticas no Estado. Ao pensar a inseparabilidade do cuidado e da política, o SMR vem buscando produzir saúde e Redução de Danos em um sentido ampliado tanto no atendimento do usuário, quanto na relação com a rede e com a cidade. Tarefa difícil e complexa, onde não há caminhos já definidos. Para tanto, o serviço busca sustentação numa ética do cuidado que tem a tenacidade de conseguir traçar caminhos, linhas de fuga e pensar o problema da rua, 
como um problema que se coloca não só àquele que vive na rua, mas a rede de saúde como um todo, e no limite, à cidade. Construir pontes de comunicação entre as diferenças (Macerata, 2010), entre as diferentes cidades que compõe a cidade do Rio de janeiro, conceber o espaço público como espaço de convivência e troca entre diferentes, esta é a função clinico/política do dispositivo em questão, esta é nossa aposta. Reduzir danos nos membros da equipe e nos assistidos é trabalhar laços, é enlaçar-se na militância política que vai ampliando bordas e tornando possível o que antes era o campo do impossível. Construir e responder à demandas de saúde a partir do território da rua é via de análise e intervenção em toda uma cidade.

\section{Nota}

${ }^{1}$ A nova Política Nacional de Atenção Básica (2012) institui, através das portarias 122 e 123 de 25 de janeiro de 2012, as Equipe de Consultório na Rua (ECR). Definidas como equipes multiprofissionais, agregando profissionais da tradicional Estratégia de Saúde da Família (ESF) e profissionais da Saúde Mental, o desenho das ECR advém de uma reformulação da proposta das equipes de Consultório de Rua, que eram de gestão da Saúde Mental, e tinham como foco de atendimento jovens usuários de substâncias psicoativas, trabalhando na lógica da Redução de Danos. As ECR, agora de gestão da Atenção Básica (AB), visam atender a integralidade da pessoa em situação de rua, incluindo na $\mathrm{AB}$ as ofertas de saúde da saúde mental: a Redução de Danos, os atendimentos a transtornos mentais e afetivos, articulando-as às ofertas tradicionais das ESF.

\section{7-Referências}

Brasil. Ministério da Saúde. Política Nacional de Atenção Básica. Brasília: Ministério da Saúde, 2012. Fuão, F. (2001). Canyons: Av. Borges de Medeiros e o Itaimbezinho. Porto Alegre: FUMPROARTE.

Guattari, F. (1992). Caosmose. Rio de Janeiro: Ed.34.

Macerata, I. (2010)“... como bruxos maneando ferozes": relações de cuidado e de controle no fio da navalha. Experiência "psi” em dispositivo da política de assistência social para crianças e adolescentes em situação de rua. Dissertação de mestrado do Programa de Pós Graduação em Psicologia "Estudos da Subjetividade", UFF. 
Experiência POP RUA: Implementação do "Saúde em Movimento nas Ruas"...

Iacã Machado Macerata: Possui graduação em Psicologia pela Pontifícia Universidade Católica do Rio Grande do Sul (2005) e mestrado em Psicologia pela Universidade Federal Fluminense (2010). Atualmente é doutorando em psicologia pela Universidade Federal Fluminense. Tem experiência na área de Psicologia, com ênfase na clínica.
Atua principalmente nos seguintes temas: articulação entre clínica e política, saúde coletiva e população em situação de rua e políticas públicas.

E-mail: imacerata@hotmail.com

Recebido em: 01/10/2013 - Aceito em: 29/10/2013 